\title{
Pathogenesis of diabetes mellitus
}

\author{
K. W. TAYLOR ${ }^{1}$
}

From the Diabetic Department, King's College Hospital, London

Diabetes, like hypertension, is not a single disease entity. Indeed its aetiology, even in a single individual, is likely to involve the interplay of a host of factors. However, there are types of diabetes in which certain causative elements can be seen to be predominant. The clinical and experimental aspects of each of these will be described.

\section{DIABETES DUE TO INSULIN DEFICIENCY}

Following the discovery of von Mering and Minkowski (1889) that diabetes followed pancreatectomy, and the later discovery that a pancreatic hormone, insulin, would reverse all the changes characteristic of diabetes, it became natural to regard diabetes mainly as an insulin-deficiency syndrome. Certainly many cases of human diabetes are due to deficiency of insulin, as evidenced by the low blood insulin levels, an observation first made over 15 years ago (Bornstein and Lawrence, 1951). This type of diabetes is typically seen in the young. Figure 1 shows serum insulin levels in such patients.

The onset is often sudden. Hyperglycaemia may be intense and ketonuria marked. There is in addition a considerable loss of urinary nitrogen due to excessive gluconeogenesis. Diabetes of this type does not differ radically from that seen, for

${ }^{1}$ Present address: School of Biological Sciences, University of Sussex, Falmer, Sussex.

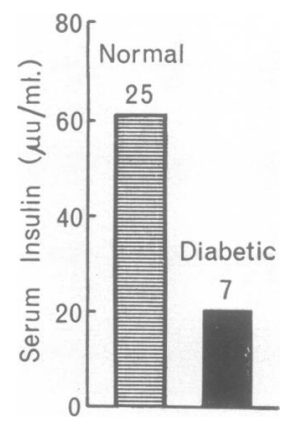

FIG. 1. Blood insulin (and glucose) in young diabetic patients at onset of their disease. Values given are means, and numbers above the cross hatched blocks refer to numbers in each group. The blood glucose level in normals was 98 $\mathrm{mg} / 100 \mathrm{ml}$ and in diabetics 300 to $1,000 \mathrm{mg} / 100 \mathrm{ml}$.

example, in totally depancreatized rats or dogs. In man some degree of partial pancreatic recovery is not too infrequent (Taylor, 1960), but total remission has rarely, if ever, been recorded.

In one case, recently under our care, a boy of 17 showed a blood glucose level of $400 \mathrm{mg} / 100 \mathrm{ml}$ on admission and intense ketonuria. His blood insulin was scarcely measurable and he needed immediate insulin therapy. After six months his insulin requirements fell rapidly and he had to be taken off it on account of repeated hypoglycaemic attacks. He has now had no insulin or other therapy for two years. Despite the remarkable clinical improvement, abnormalities of carbohydrate metabolism still persist. Glucose tolerance is still somewhat impaired; and although serum insulin now rises after oral glucose, the response is delayed (Table I). Cases of this type show resemblance to the partial recovery of rats made diabetic with alloxan.

\section{TABLE I}

GLUCOSE TOLERANCE AND SERUM INSULIN IN A JUVENILE DIABETIC IN REMISSION

\begin{tabular}{lllll}
\hline Time of sample $(\mathrm{hr})$ & Fasting & $\frac{1}{2}$ & 1 & 2 \\
Glucose $(\mathrm{mg} / 100 \mathrm{ml})$ & 88 & 155 & 228 & 139 \\
Serum insulin $(\mu \mathrm{u} / \mathrm{ml})$ & 16 & 26 & 35 & 43
\end{tabular}

AETIOLOGY OF INSULIN-DEFICIENCY DIABETES IN MAN

There are a number of possible reasons why serum $N$ insulin values should be low in this type of diabetic. There might, for example, be an association with pancreatitis. However, while diabetes is sometimes associated with acute pancreatitis, this is rarely the case with chronic pancreatitis, at least in western Europe. In Uganda chronic pancreatic fibrosis with diabetes is much more common, related perhaps to local nutritional factors. Moreover, a defect in insulin secretion has recently been detected in some cases of chronic pancreatitis in South Africa (Joffe, Banks, Jackson, Keller, O'Reilly, and 
Vinik, 1968). It must be emphasized, however, that most cases of acute diabetes in the young do not show evidence of pancreatitis, either clinically or histologically.

A more interesting type of pancreatic lesion which has been described in the young acute diabetic is an 'insulinitis', that is, an inflammation of the islet cells with lymphocytic infiltration (LeCompte, 1958, Gepts, 1964). A histological picture of this kind could be the result of some toxic agent such as a virus, or perhaps of an autoimmune process.

PANCREATIC TOXINS Until 1943 the only known way to produce a pancreatic type of diabetes was to perform a total pancreatomy. In that year Dunn and his colleagues first demonstrated that a chemical agent, alloxan, could achieve this. Histological examination of the pancreas showed that beta cell necrosis followed the administration of this agent within 48 hours. The precise mode of action of alloxan is still uncertain, but recent studies by ourselves and others have shown that it destroys the cytostructure of the islet cell. Impairment of insulin synthesis is not the primary event but follows destruction of the islet cells. Studies of the diabetes induced by alloxan have proved valuable in demonstrating the biochemical nature of diabetes, but have not contributed materially to an understanding of its aetiology in man. Alloxan has never been demonstrated in human serum despite intensive efforts.

After the discovery of the diabetogenic effects of alloxan, many other substances were shown to be diabetogenic by direct toxic action on the beta cells. Among these were dehydroascorbic acid and various chelating agents such as 8-hydroxyquinoline and ethylene diamine tetracetic acid (EDTA); it was suggested that the chelating agents might react with the zinc which is present in beta cells at high concentrations.

Recently clinicians have become very interested in the temporary diabetes which may result from administration of the benzothiadiazines, of which diazoxide is the most potent. Diazoxide differs from alloxan in that the diabetes produced by it is reversible. As several groups have shown, it has a direct inhibitory effect on glucose-mediated insulin release (Howell and Taylor, 1966). Another substance which shows great selectivity in its toxic effects is streptozotocin (Junod, Lambert, Orci, Pictet, Gonet, and Renold, 1967). This substance, a glucosamine derivative, can induce a diabetes which closely resembles that due to alloxan -perhaps by interfering directly with insulin biosynthesis.
There are other substances which act by interfering with carbohydrate metabolism within the islet cell. Such a substance is mannoheptulose, which is known to prevent the phosphorylation of glucose in liver. It is generally thought that glucose has to be phosphorylated within the islet in order to induce insulin secretion. Lower than normal glucose-6-phosphate levels within the islet follow the use of this agent which simultaneously depresses insulin secretion and raises the blood glucose level (Coore and Randle, 1964).

With the exception of the thiazide drugs these agents do not seem to be implicated in the pathogenesis of diabetes in man.

VIRUSES AND DIABETES One aspect of experimental diabetes which has so far received surprisingly little attention is the part played by viral agents.

In animals at least two viruses have been described which directly damage the beta cells. A strain of foot-and-mouth virus appears to have caused an epidemic of diabetes among cattle in southern Italy a few years ago, which was accompanied by histological evidence of damage to the islets of Langerhans (Pedini, Avellini, Morettini, and Conrado, 1962). Similarly, pancreatitis with islet cell damage has been demonstrated in mice infected with EMC virus (Craighead, 1960). In man there is an association of diabetes with mumps but this is rare. In a large series of young diabetics with acute onset we found that mumps antibody titres were only occasionally raised at the onset of the disease (Gamble and Taylor, unpublished). There are a number of other considerations which would be in keeping with a viral aetiology, such as the seasonal incidence of the juvenile type of diabetes. There is a need for further epidemiological investigation into this aspect of the disease.

AUTOIMMUNITY AND DIABETES The possibility that diabetes is due to antibodies made against insulin or some other component of the beta cell has been put forward by a number of workers. As is now well known, temporary diabetes may be induced in animals by the administration of heterologous insulins (Maloney and Coval, 1955; Wright, 1961). A few workers have suggested that antibodies to insulin may be present at the onset of human diabetes. However, some very careful studies recently performed by Parker and his colleagues (1968) failed to detect antibodies to insulin, in a group of juvenile diabetics, although several methods were used. So far there have been no studies reported on the presence or absence of antibodies to other constituents of the beta cell. 
Obesity very frequently accompanies diabetes. Indeed the commonest form of the disease in most west European countries is a mild diabetes affecting middleaged overweight subjects. It may perhaps be regarded as one of the penalties of affluence. However, the association between obesity and diabetes is not invariable, for there are many very obese persons whose glucose tolerance is normal, and the differentiation of obesity from diabetes has been confirmed in several centres.

In obesity uncomplicated by diabetes, secretion of insulin may be very greatly increased after glucose administration. It is supposed that the extra insulin secreted is necessary to keep the blood glucose normal in the face of insulin antagonism associated with obesity. The relative insulin resistance of obesity is well known in man, and has a counterpart in the high blood insulin levels seen in animals made obese experimentally (Hales and Kennedy, 1964). The nature of this resistance is unknown but may be related to the insulin antagonism associated with increased rates of fatty acid oxidation. There is also the possibility that obesity in some way directly affects the beta cells, making them in some way more sensitive to the insulin-liberating effects of glucose.

When diabetes accompanies obesity, insulin levels in serum may still be very high, particularly after glucose administration (Yalow and Berson, 1960; Hales and Randle, 1963; Rudnick and Taylor, 1964). This has led to the supposition that the beta cell is secreting insulin normally in this type of mild diabetic. This view is no longer tenable, as there is a growing body of evidence that even in mild diabetes accompanied by obesity the insulin response of the beta cell to glucose is significantly delayed. In consequence, blood glucose rises more rapidly than normal during the first half hour of a glucose tolerance test on such subjects, but the highest insulin levels are found only at a late stage and at high blood glucose levels. Though the magnitude of this response may appear to be very great, the response is in reality less than that of non-diabetics in whom the blood glucose has been raised by intravenous administration to the levels reached by obese diabetics.

The evidence therefore suggests that in diabetes which is associated with obesity the secretory response of islet tissue is impaired. This defect may not be apparent unless the beta cells are subjected to a stress such as obesity. Thus, when obesity is treated by a low carbohydrate diet, both glucose tolerance and serum insulin levels may return to normal.
There are many resemblances between the diabetogenic effects of pregnancy and those of obesity. Thus the need for insulin may substantially increase in pregnant diabetics, particularly towards the last trimester when insulin requirements are doubled or even trebled. Similarly in normal women the output of insulin in response to glucose is greatly increased towards the end of pregnancy (Spellacy and Goetz, 1963, Daughaday and Kipnis, 1966); after pregnancy insulin secretion returns abruptly to normal.

Results of this type suggest that pregnancy is associated with insulin resistance, which is possibly mediated by placental lactogen, a growth-hormonelike material derived from the placenta. Most women are in fact able to withstand the additional strain of pregnancy on islet cell function without any change in glucose tolerance, so that sufficient insulin is secreted to compensate for the associated insulin resistance. There is, however, a very small group of women in whom insulin secretion is inadequate during pregnancy, and in whom a temporary diabetes may develop (Kalkhoff, Schalch, Walker, Beck, Kipnis, and Daughaday, 1964).

ENDOCRINE SECRETIONS OTHER THAN INSULIN AND DIABETES IN MAN

Some hormones other than insulin may be involved in the aetiology of diabetes, but such associations are rare and do not account for diabetes in more than a handful of cases.

GROWTH HORMONE The association between acromegaly and diabetes has been known since the end of the last century. It is perhaps not always so well appreciated that only a relatively small percentage of patients with acromegaly become frankly diabetic, the reported incidence ranging up to $25 \%$. Diabetes is particularly common in acromegalics who have a family history of diabetes (Coggeshall and Root, 1940). Animal experiments have thrown a good deal of light on the mechanism. Young (1937) first showed N that injection of anterior pituitary extracts into normal dogs could give rise to a permanent diabetes. This work extended that of Houssay and his col- $\omega$ leagues who, several years earlier, had indicated that the pituitary elaborated anti-insulin factors, since hypophysectomy increased insulin sensitivity $\overparen{D}$ (Houssay and Biasotti, 1931). It was subsequently shown that highly purified growth hormone was diabetogenic in cats but the doses necessary to produce such effects are very large. In normal human subjects too, very high doses of human 
growth hormone are necessary to produce similar effects, such as a rise in the level of blood ketone bodies. I: is therefore rather difficult to induce diabates in man by administering growth hormone.

Thie mechanism of action of growth hormone in inducing diabetes is now thought to involve a direct effect on adipose tissue leading to increased ratty acid brealdown. This results in insulin antagonism and, as in pregnancy or obesity, extra insulin has to be secreted in order to keep the blood sugar normal. Blood insulin levels may therefore be very high in acromegaly, an observation first made using isolated rat diaphragm to assay insulin (R.andle, 1954).

While a minor rise in blood glucose levels, occasioned by insulin antagonism, may be responsible for insulin hypersecretion, it is also quite possible that some metabolite derived from fat breakdown may exert a direct effect on the beta cell. In man neither long-chain fatty acids nor $\beta$-hydroxybutyrate seems to have such an action. Growth hormone itself has no direct effect on insulin release (Coore and Randle, 1964) but does have an effect on insulin synthesis (Taylor, 1969).

Since the majority of acromegalics do not become diabetic, the functional reserves of the islets must be very considerable. It seems likely that acromegaly only induces diabetes in individuals already predisposed towards the disease. A similar viewpoint has been expressed by Cerasi and Luft (1967) in respect of other types of diabetes.

In most cases of diabetes without acromegaly which have been studied at onset, increased growth hormone secretion has not been demonstrated.

STEROIDS AND DIABETES Diabetes is a frequent accompaniment of Cushing's disease; it may also follow steroid administration in man. This type of iatrogenic diabetes is usually mild in character and bears no relationship to the insulin-resistant type of diabetes which sometimes accompanies acromegaly. Serum insulin levels are frequently normal (Karam, Grodsky, and Forsham, 1965).

The association of mild diabetes with primary hyperaldosteronism has led to the belief that excessive aldosterone secretion may also be the cause of diabetes in some hypertensives, the abnormality in insulin release being related to potassium deficiency (Conn, 1964).

However, there is no reason to believe that steroids play an important part in the aetiology of diabetes, as there is no evidence that these hormones are secreted in unusually high amounts in diabetes at onset, except occasionally in extreme ketosis.

CATECHOLAMINES AND DIABETES Diabetes may accompany phaeochromocytoma due to the inhibitory effect of catecholamines on the islet cell, as well as to their stimulatory effect on adipose tissue or on lipolysis. High concentrations of adrenaline are known to inhibit the effects of glucose on insulin release in isolated pancreatic slices.

\section{GENETIC PREDISPOSITION TO DIABETES}

That diabetes is frequently inherited has been known for a very long time. In some series there has been a family history of the disease in as many as $40 \%$ of patients. Since diabetes is almost certainly multifactorial in origin, the nature of its inheritance is too complex for a full discussion here. There are, however, certain types of inherited disorder of metabolism which may lead to diabetes and some light has been thrown on the aetiology of the disease by a study of the various hereditary syndromes in animals. There are now a large number of these conditions, which apparently differ in their mode of producing diabetes. Several are associated with obesity.

There are, for example, several strains of obese hyperglycaemic mice. In the American strain most studied, particularly by Mayer (1960), obesity and hyperglycaemia are associated with relative insulin resistance, though ketosis is absent. The beta cells are very large and serum insulin levels are high, so that primary deficiency in the ability to secrete insulin does not appear to be the cause of the diabetes in such animals. It has been suggested that the obesity is due to an unusually high activity of the enzyme glycerol kinase, which phosphorylates glycerol as the first step in the resynthesis of triglyceride; this could lead to excessive fat deposition. There are also New Zealand and Israeli strains of fat mouse, which differ in some aspects from the American strain.

By contrast a strain of obese rat exists, the sand rat, which develops diabetes when placed on a laboratory diet high in carbohydrate. These animals may show ketosis, the circulating insulin may be low, and islet cell lesions have been described. It would therefore appear that the metabolic lesion in these animals is different from that in obese mice.

Not every type of hereditary diabetes in animals is associated with obesity. For example, the Boston strain of diabetic Chinese hamster is not usually obese. Ketosis may be present. Thus there appears to be no single type of metabolic abnormality leading to diabetes which is common to all experimental animals.

Studies of the type of diabetes in man which appears to be inherited have been directed towards 
the metabolic abnormality found among the close relatives of diabetics. These have indicated that a rather higher blood glucose level may be present among such relatives, who are apparently normal, than among normal controls (Fajans and Conn, 1965).

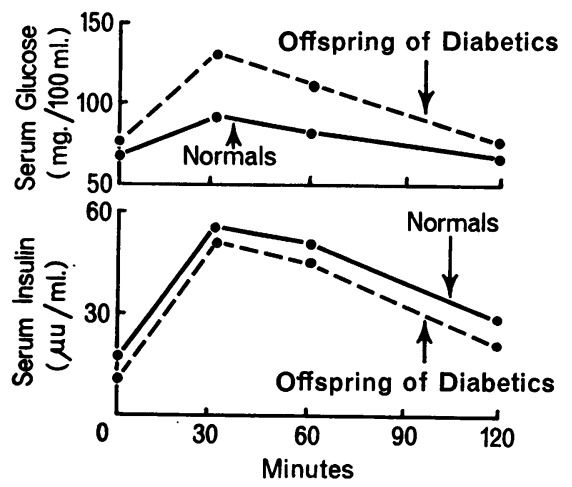

FIG. 2. Mean blood glucose (top) and insulin levels after oral glucose in six unrelated offspring of diabetic couples.

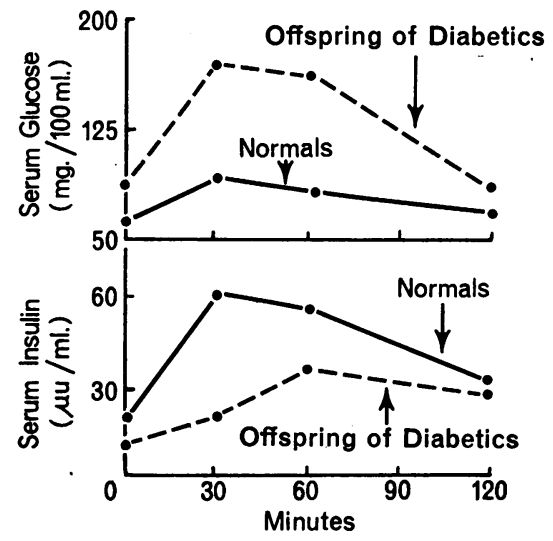

FIG. 3. Mean blood glucose (top) and insulin levels after oral glucose in nine offspring of a diabetic couple.

Several groups of workers have recently become very interested in the serum insulin response to glucose in close relatives of diabetics and in unaffected identical twins of known diabetics (Pyke and Taylor, 1967; Taylor, Pyke, Sheldon, and Oakley, 1967). A study of the insulin response to oral glucose in the offspring of diabetic couples (Fig. 2) shows that glucose tolerance is slightly abnormal, though the insulin response is almost unchanged. This implies that less insulin is being secreted for a given level of blood glucose than in the normal group. None of the offspring were considered to be diabetic. A similar study was made $\stackrel{S}{S}$ of several apparently unaffected children in one family where both parents were diabetic (Fig. 3);음 the glucose response was raised, and the secretion $\frac{\bar{N}}{\vec{D}}$ of insulin was delayed as well as reduced in quantity. $\stackrel{\mathbb{Q}}{\varrho}$ In identical twins of diabetics, again supposedly unaffected, the same type of result was obtained (Pyke and Taylor, 1967).

The nature of the abnormality appears to be a $\overrightarrow{\vec{\omega}}$ defective ability of the beta cell to respond to glucose. This abnormal response may reflect a defect in the metabolism of the islet cell. Defective is phosphorylation of glucose by a regulatory enzyme such as a hexokinase might be responsible. Alternatively, since the pentose phosphate pathway is now $/$ considered to be important in insulin secretion, there is the possibility that the activity of an enzyme? which regulates glucose flow along this route may be altered; such a regulatory enzyme could be glucose-6-phosphate dehydrogenase.

At present such ideas are purely speculative, as are other suggested genetic lesions in diabetes $\vec{\theta}$ such as the inheritance of insulin antagonism 8 (Vallance-Owen, 1964), or the secretion of abnormal insulins whose amino-acid sequence differs from that of normal individuals.

\section{GENERAL SUMMARY}

In general it can be said that, although the direct causative factor in the genesis of diabetes can be recognised in a very few individuals, the aetiology of the disease in most diabetics is completely unknown.

There is clearly a potent genetic element, ill understood but probably associated with an inadequate insulin secretion in response to glucose (Luft and Cerasi, 1968). Superadded to this, factors such as obesity, pregnancy, or other endocrine 9 factors may determine the onset of the disease. Finally there is a strong likelihood that an additional acquired factor may be important in inducing a direct destructive effect on the islet cell. Such a o factor may be toxic, autoimmune or perhaps viral, of which the last, perhaps, may be the most likely, N though this is very far from proven.

I am very much indebted to Mrs Norah Campbell for allowing me to refer to unpublished studies of blood insulin in pregnancy.

\section{REFERENCES}

Bornstein, J., and Lawrence, R. D. (1951). Brit. med. J., 1, 732. 
Cerasi, E., and Luft, R. (1967). Acta endocr. (Kbh.), 55, 330.

Coggeshall, C., and Root, H. F. (1940). Endocrinology, 26, 1.

Conn, J. W. (1964). New Engl. J. Med., 273, 1135.

Coore, H. G., and Randle, P. J. (1964). Biochem. J., 93, 66.

Craighead, J. E. (1960). Amer. J. Path., 48, 375.

Daughaday, W. H., and Kipnis, D. M. (1966). Rec. Progr. Hormone Res., 22, 49.

Dunn, J. S., Sheehan, H. L., and McLetchie, N. G. B. (1943). Lancet, 1,484

Fajans, S. S., and Conn, J. W. (1965). In On the Nature and Treatment of Diabetes, edited by B. S. Leibel, and G. A. Wrenshall, p. 641 Excerpta Medica Foundation, Amsterdam.

Gepts, W. (1964). In The Structure and Metabolism of the Pancreatic Islets, edited by S. E. Brolin, B. Hellman, and H. Knutson, p. 513. Pergamon, Oxford.

Hales, C. N., and Kennedy, G. C. (1964). Biochem. J., 90, 620 , and Randle, P. J. (1963). Lancet, 1, 790.

Howell, S. L., and Taylor, K. W. (1966). Ibid., 1, 128.

Houssay, B. A., and Biasotti, A. (1931). Endocrinology, 15, 511.

Joffe, B. I., Bank, S., Jackson, W. P. U., Keller, P., O'Reilly, I. G., and Vinik, A. I. (1968). Lancet, 2, 890

Junod, A., Lambert, A. E., Orci, L., Pictet, R., Gonet, A. E., and Renold, A. E. (1967). Proc. Soc. exp. Biol. (N.Y.), 126, 201.

Kalkhoff, R., Schalch, D. S., Walker, J. L., Beck, P., Kipnis, D. M., and Daughaday, W. M. (1964). Trans. Ass. Amer. Phycrs, $77,270$.

Karam, J. H., Grodsky, G. M., and Forsham, P. H. (1965). Ann. N.Y. Acad. Sci., 131, 374

Luft, R., and Cerasi, E. (1968). Diabetologia, 4, 1.

LeCompte, P. M. (1958). Arch. Path., 66, 450.

Mayer, J. (1960). Amer.J. clin. Nutr., 8, 712.

von Mering, J., and Minkowski. O., (1889). Arch. exp. Path., 26, 371.

Moloney, P. J., and Coval, M. (1955). Biochem. J., 59, 179.

Parker, M. L., Pildes, R. S., Caho, K. L., Cornblath, M., and Kipnis, D. M. (1968). Diabetes, 17, 27.

Pedini, B., Avellini, G., Morettini, B., and Comodo, H. (1962). Atti Soc. ital. Sci. vet., 16, 443.

Pyke, D. A., and Taylor, K. W. (1967). Brit. med.J., 4, 21.

Randle, P. J. (1954). Lancet, 1, 441.

Rudnick, P. A., and Taylor, K. W. (1965). Brit. med. J., 1, 1225.

Spellacy, W. N., and Goetz, F. C. (1963). New Engl.J. Med., 268, 988.

Taylor, K. W. (1960). Brit. med.J., 1, 1853.

(1969). In Proc. 3rd int. Congr. Endocr., in press.

Sheldon, J., Pyke, D. A., and Oakley, W. G. (1967). Brit. med. J., 4, 22.

Vallance-Owen, J. (1964). Ciba Fdn. Colloq. Endocr., 15, 217.

Wright, P. H. (1961). Amer. J. med., 31, 892.

Yalow, R. S., and Berson, S. A. (1960). J. clin. Invest., 39, 1157.

Young, F. G. (1937). Lancet, 2, 372. 